\title{
DA MESOPOTÂMIA ÀS TAPIOQUEIRAS DE OLINDA O PENSAMENTO CONTÁBIL SE REVELA
}

\section{FROM MESOPOTAMIA TO THE TAPIOQUEIRAS OF OLINDA, THE ACCOUNTING RATIONAL IS REVEALED}

\section{DE MESOPOTAMIA A LAS TAPIOQUEIRAS DE OLINDA EL PENSAMIENTO CONTABLE SE REVELA}

\section{LUIZ CARLOS MIRANDA}

PhD pelo Program In Agribusiness - University of Illinois - Professor da Universidade Federal de Pernambuco - UFPE - Líder do Grupo de Pesquisa em Utilização da Contabilidade Gerencial nas Pequenas e Médias Empresas. Endereço: Av. dos Funcionários, s/n, Cidade Universitária. CEP: 50740-580 - Recife-PE, Brasil, Telefone: (81)21268874.

E-mail: Ic-miranda@uol.com.br

\section{SHEILA SAYURI KATAOKA}

Mestre pelo Programa de Pós-Graduação em Ciências Contábeis - Universidade Federal de Pernambuco - Professora da Universidade Federal da Paraíba - Participante do Núcleo Interdisciplinar de Pesquisa em Ciências Contábeis e Atuária. Endereço: Rua Dr. Manoel de Almeida Belo, no 1241 apt 202 Bairro Novo. CEP: 53030-030 - Olinda-PE, Brasil, Telefone: (81) 34347703. E-mail: sheilakataoka@ig.com.br

\section{JOSENILDO DOS SANTOS}

Doutor em Matemática pela University of Wisconsin - Madison - Pós-Doutor em Contabilidade e Atuária pela USP-FEA - Professor da Universidade Federal de Pernambuco - Líder do Núcleo Interdisciplinar de Pesquisa em Ciências Contábeis e Atuária. Endereço: Av dos Economistas, s/n Cidade Universitária. CEP: 50670-901 - Recife-PE, Brasil, Telefone: (81) 21268369, Ramal: 202. E-mail: jsnipcontabeis@yahoo.com.br 


\section{GABRIELA MONTEIRO DA COSTA SILVEIRA}

Graduanda do Curso de Ciências Contábeis da Universidade Federal de Pernambuco - Participante do Núcleo Interdisciplinar de Pesquisa em Ciências Contábeis e Atuária. Endereço: Av. dos Economistas, s/n Cidade Universitária. CEP: 50670-901, Recife-PE, Brasil, Telefone: (81) 94063288. E-mail: gabizinhamdc@hotmail.com

\section{RESUMO}

Esta pesquisa tem por objetivo investigar o modo como é desenvolvido o controle patrimonial pelos microempresários, aqui representados pelas tapioqueiras do Alto da Sé da cidade de Olinda. Para tal, foi realizada a aplicação de questionários em uma amostra de 32 tapioqueiras lotadas no Alto da Sé e cadastradas pela associação, além de entrevista não estruturada com a presidente da associação. A pesquisa analisou aspectos relacionados à identificação das pessoas envolvidas nesse tipo de atividade, às práticas de gestão financeira adotadas pelas tapioqueiras e à percepção delas sobre os conceitos teóricos contábeis. A conclusão apresentada pelo estudo é que o controle patrimonial desenvolvido pelas tapioqueiras do Alto da Sé da cidade de Olinda acontece por meio de uma lógica própria, empírica, não uniformizada. O pensamento contábil se revela em sua forma elementar e com interpretações diferentes para os signos apresentados pela terminologia contábil. Dessa forma, esse estudo contribui para identificar as práticas de controle econômico-financeiro e o uso ou conhecimento da linguagem contábil pelos pequenos comerciantes do País.

Palavras-Chave: Negócio Informal; Controle Patrimonial; Semiótica.

\section{ABSTRACT}

This research aims to investigate the method by which the asset control of microbusinesses is developed, as represented here by the tapioqueiras of Alto da Sé in the city of Olinda. To this end, the application of questionnaires were conducted on a sample of 32 tapioqueiras crowded into Alto da Sé and registered by the association, as well as non-structured interview with the president of the association. The research revealed issues related to the identification of persons involved in this type of activity, financial management practices adopted by the tapioqueiras, and the perception of the same as to theoretical accounting concepts. The conclusion presented by this study is that the asset control developed by the tapioqueiras of Alto da Sé in the city of Olinda functions through its own empirical and irregular logic, by which accounting rational is revealed in its basic form and with different interpretations of the signs presented by accounting terminology. Thus, this study contribu- 
tes to the identification of financial-economic control practices and use, or knowledge, of the accounting language by small traders in the country.

Keywords: Informal Business; Asset Control; Semiotics.

\section{RESUMEN}

Esta pesquisa tiene por objetivo investigar el modo como se desarrolla el control patrimonial por los microempresarios, aquí representados por las tapioqueiras de Alto da Sé de la ciudad de Olinda. Para tal, fue realizada la aplicación de cuestionarios en una muestra de 32 tapioqueiras que trabajan en el Alto da Sé y catastradas por la asociación, además de entrevista no estructurada con la presidente de la asociación. La pesquisa reveló aspectos relacionados a la identificación de las personas involucradas en ese tipo de actividad, a las prácticas de gestión financiera, adoptadas por las tapioqueiras y a la percepción de las mismas sobre los conceptos teóricos contables. La conclusión presentada por el estudio es que el control patrimonial desarrollado por las tapioqueiras de Alto da Sé de la ciudad de Olinda acontece a través de una lógica propia, empírica, no uniformizada, donde el pensamiento contable se revela en su forma elemental y con interpretaciones diferentes para los signos presentados por la terminología contable. De esta forma, este estudio contribuye para identificar las prácticas de control económico-financiero y el uso o conocimiento del lenguaje contable por los pequeños comerciantes del País.

Palabras Clave: Negocio Informal; Control Patrimonial; Semiótica.

\section{INTRODUÇÃO}

Esta pesquisa tem por objetivo investigar o modo como é desenvolvido o controle patrimonial pelos empresários, aqui representados pelas tapioqueiras do Alto da Sé da cidade de Olinda. Esses comerciantes têm importância histórica e no fomento do turismo da cidade. De acordo com a Secretaria do Patrimônio, Ciência, Cultura e Turismo da Prefeitura Municipal de Olinda, a cidade recebe mensalmente 8.000 turistas, que visitam as igrejas do sítio histórico e vão ao Alto da Sé para comprar artesanato e comer tapiocas.

Tombada como Patrimônio Imaterial e Referência Cultural da Cidade, a tapioca recheada com coco do Alto da Sé foi considerada pela Revista Veja como a melhor tapioca da região pelo sexto ano consecutivo (REVISTA VEJA, 2008). As tapioqueiras do Alto da Sé são conhecidas mundialmente. Segundo a Associação das Tapioqueiras e Artesões de Arte e Artesanato do Alto da Sé e de Olinda Geral (ATAAA), pessoas de diversos lugares do mundo principalmente França, Itália, Inglaterra e Alemanha, além de toda a Grande Recife visitam constantemente Olinda especificamente para comer a tapioca (FERRÃO, 2009). 
Apesar de conhecida mundialmente e de contribuir como elemento da cultura gastronômica de Pernambuco, a tapioca, conforme enfatiza a presidente de associação, necessita de um trabalho de marketing estratégico para aumentar a sustentabilidade das tapioqueiras.

Estudos do Sebrae mostram que os orçamentos públicos já reconhecem a importância dos conglomerados de pequenos negócios para o crescimento sustentável do País em longo prazo, porém ainda faltam ações mais direcionadas para os pequenos empreendedores (SEBRAE, 2005).

Conhecer como os microempresários manipulam conceitos contábeis e financeiros é importante pela participação desses empresários na economia brasileira. Segundo o Sebrae (2005), em 2003, existiam 10,3 milhões de empreendimentos informais. Deve-se considerar, porém, que o número encontrado depende da definição e dos critérios usados nos levantamentos e nas pesquisas. O IBGE, em estudo realizado em parceira com o Sebrae, divulgou, em julho de 2005 , o resultado de uma pesquisa, indicando que $98 \%$ das pequenas empresas brasileiras são informais.

Essa pesquisa destina-se a conhecer de que modo é desenvolvido o controle patrimonial pelas tapioqueiras do Alto da Sé. O estudo se propõe a identificar as práticas de controle econômico-financeiro e o uso ou conhecimento da linguagem contábil desse grupo de comerciantes.

O presente estudo está estruturado em cinco seções, além desta introdução e das referências. A seção dois apresenta a revisão da literatura; a seção três descreve a metodologia utilizada pelo estudo; e as duas seguintes, respectivamente, os resultados e as conclusões.

\section{BREVE HISTORICO SOBRE A TAPIOCA DO ALTO DA SÉ}

De acordo com a Associação Brasileira de Produtores de Amido de Mandioca, a história da tapioca está associada à cultura dos índios. Ela é elaborada a partir da farinha-depau, de manic ou manihot - hoje mandioca (Manihot esculenta crantz). Era feita ralando-se a raiz que cresce dentro da terra em três ou quatro meses. Depois de arrancá-la, secavamna ao fogo ou ralavam-na, ainda fresca, em uma prancha de madeira cravejada de pedrinhas pontudas, reduzindo-a a uma farinha alva, empapada, que ia para um recipiente comprido, de palha trançada - tipiti - para escorrer e secar (ABAM, 2009).

A herança da culinária indígena está presente em todo o País. Em algumas áreas do Nordeste, a tapioca é uma farinha granulada, usada para preparar bolos, cremes, pudins e cuscuz. Em outras, é o nome de um prato também conhecido como beiju - espécie de panqueca preparada com a goma da mandioca. A tapioca ainda pode ser feita com farinha de tapioca refinada ou polvilho doce. A facilidade da goma é que ela vem "no ponto" e pode ser comprada facilmente em feiras. Já a farinha de tapioca (ou o polvilho) precisa ser umedecida com água, para se transformar em goma (LIKOUROPOULOS, 2006). 


\section{repec}

Em Olinda, o consumo da farinha, do beiju e da tapioca - cuja matéria-prima é a mandioca - ocorre desde o século XVI, a partir da invenção, pelo colonizador, português da casa de farinha. A criação da tapioca se deu a partir do aperfeiçoamento, pelo português, do beiju indígena. De acordo com informações da Secretaria de Patrimônio, Ciência, Cultura e Turismo da Prefeitura Municipal de Olinda, a venda da tapioca iniciou-se na década de 70, com uma senhora conhecida como dona Conceição, que passou a preparar e comercializar tapiocas como forma de sobrevivência (LINS, 2006).

Em 2006, a tradicional tapioca que contém recheio de coco seco ralado, vendida no Alto da Sé, foi tombada como Patrimônio Imaterial e Referência Cultural da cidade. Atualmente, trinta e quatro barracas de tapioca garantem a sustentabilidade de diversas famílias olindenses. $O$ movimento de valorização oficial da tapioca ainda inclui outras ações, a começar pela padronização da vestimenta das tapioqueiras da Sé. As profissionais ainda passam por capacitações de atendimento ao público e terão suas barracas mais bem sinalizadas (ATAAA, 2009).

\section{CARACTERIZAÇÃO DO NEGÓCIO INFORMAL}

É comum o negócio informal ser reconhecido como aquele que tem as suas atividades produtivas fora da lei. Existe, porém, certa complexidade em se conceituar o setor, tornando seu conceito motivo de grande controvérsia entre os estudiosos (PAMPLONA; ROMEIRO, 2003; FAURE, 2006).

Alguns parâmetros são considerados no momento de definir a informalidade: o primeiro é a questão da não declaração ao estado da atividade exercida, ou seja, atividade econômica extralegal, porém considerada socialmente lícita do ponto de vista ético. O segundo parâmetro é a forma de organização da produção, com produtividade em pequena escala e processo tecnológico simples e geralmente com atuação em mercados competitivos. O terceiro parâmetro é a inexistência de vínculo empregatício dos que atuam nessas organizações informais e a forte vinculação de seus membros com a família (NERI, 2005; FAURE, 2006).

Na visão de Lautier (1991), o que distingue em geral uma atividade econômica formal de outra informal é a sua maior ou menor subordinação à regulamentação estatal. Não se deve pensar, no entanto, que essas atividades são inteiramente separadas, constituindo "setores" bem demarcados.

As pessoas que participam da economia informal diferenciam-se, dentre outros fatores, por renda, perfil ocupacional e qualificação técnica. Os fatores que motivam essas pessoas a iniciar um negócio informal são: a falta de emprego no mercado formal, a falta de financiamento para a criação de uma atividade formal, a necessidade de complementação da renda familiar, a independência, a experiência na área, a tradição familiar, a possibilidade de um negócio promissor, o horário flexível e a oportunidade de fazer sociedade (NERI, 2005; FAURE, 2006). 
Segundo Pamplona e Romeiro (2003), a economia informal não é um eufemismo para a pobreza (embora a maioria dos engajados nela tenda a ser pobre). O informal pode ser tanto "espaço de sobrevivência" quanto de "ascensão social". Colaborando com essa perspectiva, Faure (2006) afirma que inúmeros empregados demitidos não encontram meios de subsistência a não ser na atividade informal, ao mesmo tempo em que as camadas pobres ou empobrecidas da população encontram no informal o único modo de se abastecerem dos bens e dos alimentos para sobreviver.

Seja como um meio de subsistência ou como possibilidade de um negócio promissor, a condição de informalidade implica uma série de desvantagens para o negócio, especialmente a exclusão de mercados que exigem provas de regularidade fiscal e a dificuldade na obtenção de crédito (FAURE, 2006; LIKOUROPOULOS, 2006).

A dificuldade de obtenção de crédito deve-se ao fato de o sistema financeiro brasileiro não atender às necessidades das pequenas e das microempresas e, menos ainda, às necessidades dos trabalhadores por conta própria, empenhados em atividades das mais variadas, com as quais geram a renda única e indispensável à sua sobrevivência ou complementam os poucos recursos que recebem em outras atividades formais ou informais (CARVALHO e ABRAMOVAY, 2004).

Outro aspecto a ser considerado é o controle financeiro desse tipo de atividade. Entre as características do negócio informal, estão a indigência do sistema de contabilidade e a fusão entre o domicílio e o negócio num organismo único (CARVALHO e ABRAMOVAY, 2004; FAURE, 2006),

Por desconhecimento ou inabilidade administrativo-financeira, muitas empresas do setor informal têm suas atividades encerradas em pouco tempo de existência. $A$ falta do conhecimento e da habilidade necessária para controlar a situação econômico-financeira é um dos fatores que podem explicar a alta mortalidade desses empreendimentos.

Mas não há unanimidade quanto à essencialidade da contabilidade para a prosperidade dos negócios. Oliveira e Martins (1993), por exemplo, afirmam que a dificuldade de processar informações contábeis e financeiras úteis pode estar relacionada à continuidade ou descontinuidade de um negócio. Em contraposição, Cia e Smith (2001), em seus estudos, afirmam que uma empresa pode vir a sobreviver sem uma contabilidade ou com controles financeiros caóticos e desatualizados, desde que as vendas sejam suficientes para cobrirem os desperdícios aparentemente invisíveis. Kassai (1997) é da opinião de que a contabilidade deve pautar-se pela simplicidade, facilidade de obtenção de informações, relevância e atualidade, que possibilite ao gestor efetuar simulações e manipular as informações de forma simples, respeitando as características específicas do pequeno negócio.

No Brasil, a pouca escolaridade é uma das características que marcam o negócio informal. Dados divulgados pelo Sebrae (2005), quanto ao nível de instrução, apontam que, dos 10,3 milhões de empreendimentos informais pesquisados, $60,1 \%$ das pessoas cursa- 
ram, no máximo, até o ensino fundamental. O grau universitário completo representa 6,3\% do total dos autônomos e $18,3 \%$ dos empregadores. Do total pesquisado, apenas $24,5 \%$ afirmaram frequentar ou já ter frequentado algum tipo de curso de especialização para atuarem no negócio.

\section{OS PRIMÓRDIOS DA CONTABILIDADE E AS TAPIOQUEIRAS}

A preocupação com as propriedades e a riqueza são uma constante no homem, e ele teve de ir aperfeiçoando seu instrumento de avaliação patrimonial à medida que as atividades foram se desenvolvendo em dimensão e complexidade. Mesmo sem a escrita, a contabilidade era utilizada como forma de controle patrimonial (MARTINS, 2001; IUDÍCIBUS, 2004). É o caso da Dona Edite, uma das tapioqueiras entrevistadas, que afirma:

Aí a gente vai vendendo, quando chega no fim do mês eu coloco dentro da minha barraca umas latinhas de leite vazias (pra guardar o dinheiro). Aí quando chega, o fim de semana, o que sobra eu coloco dentro da latinha, porque compra isopor, compra toalha, compra... alguma coisa... talher,.. o que faltar... aí a gente compra mesmo, pra manutenção da barraca né? E na outra latinha eu boto (dinheiro) pra comprar mercadoria, é... a bebida, a mão de obra, tudo... tudo eu boto nas latinhas. (DONA EDITE)

As palavras de Dona Edite, dentro da proposta desse estudo, levam a um retorno no tempo nas origens históricas da Contabilidade. De acordo com Schmidt (2000), em sítios arqueológicos do Oriente próximo, foram encontrados materiais utilizados por civilizações pré-históricas que caracterizam um sistema contábil utilizado entre 8.000 e 3.000 a.C., constituído de pequenas fichas de barro onde eram controlados o patrimônio e o fluxo de produtos.

As fichas de barro foram usadas abundantemente como forma de representação de uma unidade de mercadoria específica. Antes de 3.250 a.C., as fichas não eram armazenadas de forma adequada; após essa data, passaram a ser preservadas em pequenas caixas de barro, denominadas de envelopes de barro. Simultaneamente à criação dos envelopes, existia um sistema alternativo, no qual as fichas perfuradas eram armazenadas e amarradas juntas por uma espécie de lacre de barro. O devedor era identificado por um selo colocado em volta do envelope ou mediante impressão sobre o lacre (SCHMIDT, 2000).

Posteriormente às fichas de barro, as tábuas de argila das cidades Uruk e Ur, na Mesopotâmia, representam fortes evidências do controle físico dos bens, visto que ainda não existia o conceito de valor moeda. Vários registros contábeis desse período foram encontrados também no Egito, demonstrando a forma como os agricultores pagavam com alimentos os coletores de tributos. E na China, onde registros contábeis sofisticados de- 
notam familiaridade com o sistema de partidas dobradas (HENDRIKSEN e BREDA, 1999; SCHMIDT, 2000).

Por volta de 2000 a.C, os livros e documentos comerciais já eram obrigatórios no Egito, com escrituração das contas com base no valor de sua moeda. A utilização do dinheiro como meio de troca, através de metais preciosos como ouro e prata, facilitava as trocas. Entretanto, os mercados permaneceram simples por causa da natureza descomplicada das funções de demanda e oferta (KAM, 1985; HENDRIKSEN e BREDA, 1999; MARTINS, 2001).

Sobre a comercialização existente na Antiguidade, alguns fatores devem ser levados em consideração, tais como: as empresas eram geralmente pequenas e pertencentes a famílias; o trabalho era executado por membros da família, servos ou escravos; a captação de recursos pelos comerciantes era uma transação direta (escambo) com indivíduos específicos e produção em pequena escala (KAM,1985).

As atividades empresariais eram mínimas, os pequenos comerciantes e artesões necessitavam apenas de informações simples sobre suas contas a receber, total de suas dívidas, prazo de vencimento e beneficiários (SCHMIDT, 2000).

Considerando a forma como estavam estruturados os mercados e as características de comercialização na Antiguidade, bem como forma de controle patrimonial relatado por Dona Edite, leva a compreensão de que a gestão dos pequenos negócios informais existentes na atualidade assemelha-se ao pensamento contábil encontrado nas antigas civilizações.

Dentro dessa contabilidade simplificada, Hendriksen e Breda (1999) alertam para os contrastes existentes entre os métodos e as teorias contábeis atuais, sendo estes: inexistência de padrões mínimos de uniformidade de divulgação; não existência de distinção clara entre os negócios pessoais e empresariais; falta do conceito de exercício contábil para apuração de resultados; e ausência de uma única unidade monetária estável.

Esses contrastes, entretanto, não invalidam a existência de um sistema contábil. De acordo com ludícibus (2004), pode-se facilmente verificar que um sistema simples de registro e análise contábil não falta nem mesmo na mais rudimentar das organizações.

\section{SEMIÓTICA E A INFORMAÇÃO CONTABIL}

A informação contábil tem sido objeto de diversos estudos com a finalidade de diminuir as distorções de entendimento e aproximar a Contabilidade de seus usuários. Em seus estudos, Dias et. al. (2004) afirmam que os ruídos presentes na comunicação, tais como terminologia contábil inadequada, quantidade de informações divulgadas, uso de expressões e termos em outros idiomas, dificultam o processo de comunicação.

Considerando que a função básica da Contabilidade é fornecer informações sobre a riqueza das organizações a diversos estratos de usuários, e que o entendimento dessa informação é um dos requisitos para que ela assim se caracterize, há de se questionar 


\section{repec}

se, atualmente, tais informações se apresentam compreensíveis aos seus destinatários (NAKAGAWA e PRETTO, 2000).

Sobre a compreensão da informação contábil, llufi (2000) explica que uma mensagem contábil é encontrada ou está contida num mesmo código linguístico, o que significa que a mensagem é diferente já no momento da emissão dos signos (códigos) para expressá-la. Para entender uma mensagem contábil, é necessário, primeiro, interpretar (decodificar) os signos que a mensagem contém.

Neste aspecto, a Teoria da Comunicação estabelece como processo comunicativo o fluxo de informações partindo do emissor (contador), enviando a mensagem (informação contábil) ao receptor (usuário) através de um canal (relatórios contábeis), por meio de um código, sujeito a interferências (ruídos) no envio da mensagem (MORAES, NAGANO e MERLO, 2004; ILUFI, 2000),

Embasados na Teoria da Comunicação, Hendriksen e Breda (1999) ensinam que uma das classificações das teorias contábeis se apoia na noção de que a Contabilidade é uma linguagem e que essa disciplina tem sido considerada por muitos como a linguagem dos negócios. Esses autores acrescentam que, a respeito de uma linguagem e das palavras utilizadas pela Contabilidade, podem ser analisadas dentro dos aspectos pragmático, semântico e sintático.

Partindo do pressuposto de que a Contabilidade de fato é uma espécie de linguagem, diversos autores entendem que a semiótica pode fornecer metodologia útil para se interpretarem relatórios e corrigirem eventuais distorções que se manifestem no processo de geração e comunicação das informações contábeis.

A semiótica ou semiologia, conhecida como a ciência dos signos, é a mais jovem das ciências humanas. Em seus estudos, Eco (2000) explora as possibilidades teóricas e as funções sociais de um estudo unificado de todo e qualquer fenômeno de significação e/ ou comunicação. Dentro da Teoria dos Códigos e da Teoria da Produção Sígnica, o autor apresenta a semiótica como o estudo sígnico sob três pontos de vista: o sintático, que estuda as relações dos signos entre si; o semântico, que tem por objeto o vínculo do signo com a realidade que ele exprime; e o pragmático, que examina a relação entre os signos.

Etheridge (1990) propõe que a semiótica seja utilizada como instrumento de apoio à avaliação dos aspectos semânticos, sintáticos e pragmático da informação contábil.

Por sua vez, llufi (2000) defende a ideia de que a Teoria da Semiótica e a Teoria da Comunicação devem ser incorporadas ao processo de formação universitária do contador no Chile. Segundo o autor, relacionar a semiótica à Contabilidade instrumentaliza enormemente o contador a participar e adaptar a informação contábil no âmbito da dimensão pragmática, segundo as demandas dos diferentes usuários que se servem da contabilidade para tomar decisões.

No Brasil, Nakagawa (2000, 2001, 2002, 2003, 2004) conduziu diversos estudos aplicando a semiótica à evidenciação contábil, observando que muitos dos termos empregados geram significados diferentes dos pretendidos pelos produtores das informações ou apresen- 
tam-se divergentes no que se refere ao significado léxico. O autor constatou também que a Contabilidade é citada ora como linguagem, ora como registro, informação ou profissão. E defende que a semiótica pode fornecer instrumental metodológico para auxiliar na identificação, observação e análise dos fenômenos que provocam variações patrimoniais.

A aplicação da semiótica à Contabilidade contribuiu para identificar alguns problemas de comunicação. Dias et. al. (2004), por exemplo, alertam que muitas vezes os signos contábeis (sinais usados para a comunicação da informação contábil) não despertam a mesma percepção em diferentes observadores, causando falhas na comunicação. De acordo com o autor, a questão semiótica na Contabilidade não se atém apenas a relações semânticas internacionais; mesmo diferentes grupos de usuários podem apresentar diferentes interpretações de um mesmo signo.

Um dos principais problemas, que não é exclusivo da Contabilidade, é a profusão de nomes para um único conceito e também conceitos diferentes para uma única palavra. Ao se codificar uma informação com um foco tão abrangente e sendo o codificador um conhecedor desses vários códigos, pode haver certa confusão de sua parte (MARTINS, 2000; MORAES, NAGANO e MERLO, 2004).

Cunningham (2003) apresenta como exemplo os conceitos de "Justo e Verdadeiro" (conceito internacional de "The True and Fair View"). O que pode ser considerado como "justo e verdadeiro" na contabilidade na França é relativamente diferente no Japão, e ambos são diferentes do conceito alemão, mas as diferenças internacionais explicam apenas uma parte das diferenças semióticas entre países; existem questões histórias e culturais que regem a diferenciação deste conceito.

Em pesquisa realizada por Silva (1995), os resultados evidenciaram que a maioria dos pesquisados que têm opinião formada sobre o grau de entendimento das informações contidas no Balanço Patrimonial não consegue compreendê-las por completo. $\mathrm{O}$ autor recomenda, por exemplo, alterar o termo "Equivalência Patrimonial" para "Ganhos ou Perdas de nossos Investimentos em Outras Empresas", tendo em vista que boa parte dos usuários desconhece seu significado.

Esses estudos evidenciam problemas surgidos pela dificuldade de a Contabilidade divulgar informações compreensíveis aos seus destinatários.

\section{METODOLOGIA}

A metodologia empregada no estudo foi a pesquisa de campo, envolvendo as seguintes etapas: revisão da literatura, com a finalidade de delimitar com maior precisão as questões da pesquisa; entrevista com as tapioqueiras, realizada com o auxílio de um questionário com questões predominantemente fechadas; entrevista não padronizada com a presidente da associação; e análise descritiva dos dados. 
A amostra selecionada foi de trinta e quatro tapioqueiras cadastradas pela Associação das Tapioqueiras e Artesões de Arte e Artesanato do Alto da Sé e de Olinda Geral (ATAAA) que mantêm suas barracas localizadas no Alto da Sé na cidade de Olinda. Da amostra selecionada, foram aplicados trinta e dois questionários. Apenas dois comerciantes recusaram-se a participar da pesquisa, alegando falta de tempo para a entrevista.

A coleta de dados foi realizada em dois finais de semana, com os pesquisadores entrevistando os tapioqueiros (na sua maioria mulheres), com a leitura de questões de um questionário, com questões predominantemente fechadas. O pesquisador ia preenchendo o questionário à medida que lia a questão. Para não atrapalhar a atividade comercial dos entrevistados e garantir a qualidade da coleta de dados, as entrevistas ocorreram nos momentos de menor movimento comercial. Um grupo de dez tapioqueiras autorizou a gravação de suas respostas ao questionário, contribuindo para uma melhor análise dos dados. A reprodução dos trechos para esta pesquisa foi feita com fidedignidade, respeitando a linguagem e a cultura dos entrevistados, desconsiderando, portanto, regras gramaticais da língua portuguesa.

Posteriormente foi realizada uma entrevista, não estruturada, com a senhora Sandete Ferrão, presidente da ATAAA, por meio da qual foi possível coletar dados sobre a história, a organização e a estrutura do comércio de tapiocas.

A análise descritiva consiste em: análise qualitativa das entrevistas para identificar o direcionamento do estudo dos dados coletados; tabulação das respostas dos questionários; análise quantitativa através de uso de indicadores e gráficos estatísticos.

\section{ANÁLISE DOS DADOS}

$\mathrm{Na}$ identificação das tapioqueiras participantes desta pesquisa, observou-se que 29 respondentes eram do sexo feminino e apenas 3 eram do sexo masculino, com idades entre 25 e 75 anos, com maior concentração entre os 35 e 45 anos. Os registros demonstraram a maturidade dessas pessoas e também uma alternativa de renda, além da garantia de sustentabilidade para as pessoas acima de 60 anos, que representam $16 \%$ dos respondentes.

Em relação ao nível de escolaridade, é possível encontrar desde analfabetos até pessoas que cursaram o segundo grau completo, as quais representam $25,8 \%$ dos respondentes. Conforme apresentado na Tabela 1, Grau de Instrução, a maior concentração $(64,5 \%)$ está no ensino fundamental, demonstrando a pouca escolaridade dos tapioqueiros.

Esse resultado confirma os estudos de Lykouropoulos (2006), que constatou que $89 \%$ das pessoas entrevistadas cursaram no máximo o ensino fundamental, sendo esse um dos fatores motivacionais para elas optarem pelo comércio de tapiocas. 
Tabela 1 - Grau de Instrução

\begin{tabular}{|c|c|c|c|}
\hline Grau de Escolaridade & Frequência & Percentual & Percentual \\
\hline Analfabeto & 1 & 3,2 & 3,2 \\
\hline $1^{\circ}$ Ano Fundamental & 1 & 3,2 & 6,5 \\
\hline $2^{\circ}$ Ano Fundamental & 2 & 6,5 & 12,9 \\
\hline $4^{\circ}$ Ano Fundamental & 2 & 6,5 & 19,4 \\
\hline $5^{\circ}$ Ano Fundamental & 6 & 19,4 & 38,7 \\
\hline $6^{\circ}$ Ano Fundamental & 1 & 3,2 & 41,9 \\
\hline $8^{\circ}$ Ano Fundamental & 7 & 22,6 & 64,5 \\
\hline $1^{\circ}$ Ano Médio & 1 & 3,2 & 67,7 \\
\hline $2^{\circ}$ Ano Médio & 2 & 6,5 & 74,2 \\
\hline $3^{\circ}$ Ano Médio & 8 & 25,8 & 100,0 \\
\hline Total & 31 & 100,0 & \\
\hline
\end{tabular}

A idade média dos empreendimentos é de 15,4 anos, com desvio padrão de 9,4. A mediana é de 16,5 anos, com um mínimo de 2 meses e um máximo de 37 anos. A maioria $\quad(59,83 \%)$ dos entrevistados têm suas barracas há mais de 15 anos. Apenas uma tapioqueira estava no negócio há menos de 3 anos. Esses números mostram que as tapioqueiras têm taxa de mortalidade bem menor do que a maioria dos demais empreendimentos. Estudos do Sebrae revelam que a taxa de mortalidade dos pequenos negócios brasileiros é de 3 a 5 anos. Entretanto, observou-se que maior experiência no ramo afeta a renda, mas apenas até certo ponto, quando o excesso de tempo no negócio não afeta a experiência (vide Tabela 2). A renda familiar mais alta é de um mil reais mensal, informada por comerciantes que têm acima de 10 anos, o que pode ser considerado como um indicativo de estagnação ou limite no crescimento do negócio.

Tabela 2 - Renda Familiar e Tempo no Local

\begin{tabular}{|c|c|c|c|c|c|}
\hline \multirow{2}{*}{$\begin{array}{c}\text { Renda Familiarl } \\
\text { Tempo no Ponto }\end{array}$} & \multirow{2}{*}{ não sabe ou não informou } & \multicolumn{3}{|c|}{ Reais } & \\
\cline { 3 - 6 } & & $\mathbf{1}$ a $\mathbf{3 0 0}$ & $\mathbf{4 0 0}$ a $\mathbf{7 0 0}$ & $\mathbf{8 0 0}$ a $\mathbf{1 . 0 0 0}$ & Total \\
\hline 0 a 5 anos & 1 & 1 & 2 & 1 & 5 \\
\hline 6 a 10 anos & & 1 & 2 & 4 & 8 \\
\hline 11 a 15 anos & 2 & 1 & & 2 & 3 \\
\hline 16 a 20 anos & 1 & & 4 & 3 & 9 \\
\hline 21 a 25 anos & 3 & & & 2 & 3 \\
\hline acima de 26 anos & 8 & & & 1 & 4 \\
\hline Total & 1 & 3 & 8 & 13 & 32 \\
\hline
\end{tabular}


Em relação ao aperfeiçoamento para facilitar ou melhorar a rotina de trabalho, a ATAAA em parceira com o Sebrae, desenvolveu cursos de treinamento para as tapioqueiras, como o de : manipulação e higienização de alimentos e atendimento a clientes. Além desses, alguns comerciantes informaram ter participado também de outros cursos, como: noções básicas de turismo, empreendedorismo e noções básicas sobre a história de Olinda. Conforme demonstrado na Tabela 3.

Tabela 3 - Cursos de Aperfeiçoamento

\begin{tabular}{|l|c|c|c|}
\hline \multicolumn{1}{|c|}{ Tipo de Curso } & Frequência & Percentual & Percentual \\
\hline Higiene e Manipulação dos Alimentos & 8 & 25,0 & 25,0 \\
\hline Higiene e Atendimento a Clientes & 10 & 31,2 & 56,2 \\
\hline $\begin{array}{l}\text { Higiene, Empreendedorismo, Turismo e } \\
\text { Atendimento a Clientes }\end{array}$ & 1 & 3,1 & 59,4 \\
\hline Higiene, Turismo e Atendimento & 4 & 12,5 & 71,9 \\
\hline Higiene, Empreendedorismo e Atendimento & 1 & 3,1 & 75,0 \\
\hline Higiene, Turismo, Atendimento e Inglês & 1 & 3,1 & 78,1 \\
\hline $\begin{array}{l}\text { Formação de Preços, Higiene, Turismo e } \\
\text { Atendimento }\end{array}$ & 1 & 3,1 & 81,2 \\
\hline $\begin{array}{l}\text { Formação de Preços, Higiene, Atendimento e } \\
\text { Empreendedorismo }\end{array}$ & 1 & 3,1 & 84,3 \\
\hline Não fez cursos & 5 & 15,6 & 100,0 \\
\hline Total & 32 & 100,0 & \\
\hline
\end{tabular}

Dentro desse contexto, observou-se a ausência de cursos especifícos voltados ao controle financeiro e noções básicas de Contabilidade. Os comerciantes percebem também a necessidade de conhecimento básico de línguas estrangeiras, para melhor se comunicar com os turistas que vêm do exterior. Os relatos apresentados pela T29, T16 e T11 expressam essa necessidade:

T29: Tenho vontade de fazer um curso de inglês, mas nunca fui convidado.

T16: Teve um curso de idioma pra gente, mas não foi adiante; foi muito rápido o curso; foi só uma semana e uma semana não dá.

T11: Quando vêm os clientes de fora, a gente tem que desenrolar, né? Aí a gente fala coke, que é coca-cola; cheese, que é queijo, e eles tentam falar em português também e a gente se acerta... Se tivesse curso pra gente aprender a falar mais, era melhor... e também pra aprender a fazer as contas mais direitinho... ia ficar bom. 
$\mathrm{Na}$ análise dos aspectos relacionados à administração dos recursos financeiros, observou-se que a lógica utilizada pelas tapioqueiras em muito diverge do praticado pelos gestores de empresas maiores. A pesquisa revelou que, em geral, os tapioqueiros utilizam a percepção e o conhecimento do negócio como forma de controle. Os indicadores para gerenciamento das atividades estão relacionados à sazonalidade, clientela esperada e preço de compra dos produtos. O desenvolvimento das atividades é estabelecido com base no dinheiro que envolve todas as transações, no recebimento de dinheiro dos clientes (contas a receber), na reposição das mercadorias, nas contas a pagar e no lucro ou prejuízo diário ou semanal.

O controle de estoque para reposição das mercadorias é feito de forma muito rudimentar. Dos entrevistados, 46,88\% afirmam controlar o estoque apenas com os olhos, ou seja, veem se o nível dos materiais necessários está adequado ou não. A lista de compras para reposição foi apontada como alternativa para $25 \%$ das tapioqueiras e $28,12 \%$ não sabem explicar ou não responderam. Essa reposição das mercadorias é feita diariamente por $53 \%$ das tapioqueiras ou semanalmente pelas demais. No momento de negociação das compras de mercadoria em geral, o fator prioritário para $75 \%$ é a qualidade dos produtos, pricipalmente a goma. Os relatos de T15, T16, T30 e T31 ajudam na compreensão desse mecanismo:

T15: Quando a gente fecha, aí eu vou olhando e anotando pra ver o que está faltando pra gente ir comprar.

T16: Eu faço as compras de acordo com o movimento, que assim eu não tenho reserva. Eu trouxe hoje essa mercadoria aí; se vender, amanhã outra, eu faço de acordo com o que vender. (...) Eu compro de acordo com o que tá faltando.

T31: Todo dia o material tem que tá comprado.(...) Tá faltando assim... aí a gente vendo que tá perto de faltar, a gente compra logo.

T30: É a qualidade, porque o preço você pode pagar um pouco mais e substituir no preço do valor aqui, entendeu? Mas contanto que seja um material bom.

T15: Lá perto de casa têm vários mercadinhos, mas às vezes a goma não é de qualidade. Eu compro mais cara porque eu tenho onde comprar ela por $R \$ 1,30$ e compro por $R \$ 1,60$ por causa da qualidade que ela é melhor.

O controle do caixa, o que recebeu e o que gastou, em geral é feito com o auxílio do caderninho ou caderneta de anotações, como apresenta aTabela 4. 
Tabela 4 - Controle das Contas

\begin{tabular}{|l|c|c|c|}
\hline \multicolumn{1}{|c|}{ Controle das Contas } & Frequência & Percentual & $\begin{array}{c}\text { Percentual } \\
\text { Acumulado }\end{array}$ \\
\hline Caderninho de Anotações & 16 & 50,0 & 50,0 \\
\hline Olhar & 11 & 34,4 & 84,4 \\
\hline Não sabe informar & 5 & 15,6 & 100,0 \\
\hline Total & 32 & 100,0 & \\
\hline
\end{tabular}

A respondente T26 explica como é feito o controle e a anotação no caderninho e a respondente T14 comenta sobre a importância de se fazer um controle:

T26: Eu vou anotando tudo no meu caderninho. Como eu faço compra todo dia, eu junto toda nota de compra; quando chega a última semana do mês, aí eu calculo toda a nota com a anterior; aí eu vejo no final do mês quanto eu ganho ou se diminuiu, porque dia de chuva sempre a gente ganha menos, né? Mas quando é mês de sol, de verão, a gente ganha bem, ganha mais.

T14: Você fala como se fosse um caixa, de entrada e saída? A gente quase não faz, porque a gente somos dona, aí não controla muito não. Não tem um caixa de entrada e saída não. (...) Quando a pessoa trabalha pra pessoa não faz caixa, e isso é muito importante fazer caixa, porque aí sabe. A gente hoje em dia; tô trabalhando aqui, mas eu nunca sei o balanço pra ver se dá mais, se dá menos, entendeu? Um balanço de tudo pra saber o que entrou, o que saiu, o que a gente comprou.

Veja-se que a tapioqueira 14 (T14) usa a palavra "balanço" com o significado de controle do caixa (fazer um balanço de tudo o que entrou, o que saiu).

As tapioqueiras foram perguntadas sobre como elas avaliam o negócio ("Como você sabe se o mês foi bom ou não?" e "Como você sabe se está valendo a pena vender tapioca?") As Tabelas 5 e 6 apresentam o resultado das respostas:

\section{Tabela 5 - Avaliação do Retorno do Negócio}

\begin{tabular}{|l|c|c|c|}
\hline $\begin{array}{c}\text { Avaliação do Retorno } \\
\text { do Negócio }\end{array}$ & Frequência & Percentual & $\begin{array}{c}\text { Percentual } \\
\text { Acumulado }\end{array}$ \\
\hline Movimento Diário & 14 & 43,8 & 43,8 \\
\hline Quantidade Vendida & 7 & 21,9 & 65,6 \\
\hline Faturamento & 7 & 21,9 & 87,5 \\
\hline
\end{tabular}




\begin{tabular}{|l|c|c|c|}
\hline Lucro Obtido & 2 & 6,2 & 90,6 \\
\hline Quantidade Vendida e Faturamento & 1 & 3,1 & 96,9 \\
\hline Não sabe informar & 1 & 3,1 & 100,0 \\
\hline Total & 32 & 100,0 & \\
\hline
\end{tabular}

Tabela 6 - Motivação para Continuar o Negócio

\begin{tabular}{|l|c|c|c|}
\hline $\begin{array}{c}\text { Motivação para } \\
\text { Continuar o Negócio }\end{array}$ & Frequência & Percentual & $\begin{array}{c}\text { Percentual } \\
\text { Acumulado }\end{array}$ \\
\hline Falta de Opção & 3 & 9,4 & 9,4 \\
\hline Lucratividade & 18 & 56,2 & 65,6 \\
\hline Autonomia & 2 & 6,2 & 71,9 \\
\hline Gosto pela Atividade & 6 & 18,8 & 90,6 \\
\hline Por ser a tapioca & 1 & 3,1 & 96,9 \\
\hline Patrimônio Imaterial & 3 & 9,4 & 100,0 \\
\hline Total & 32 & 100,0 & \\
\hline
\end{tabular}

Em relação à determinação dos preços das tapiocas e ao cálculo da receita unitária, as tapioqueiras informaram que os preços são tabelados. Elas apresentam o cardápio contendo os produtos oferecidos e os preços, que são os mesmos em todas as barracas, embora algumas afirmam oferecer descontos para os seus clientes. Os cálculos são feitos pela associação e repassados para todos em reunião, onde há votação da nova tabela. A presidente da Associação explica como são feitos esses cálculos:

A gente vê assim, o custo, né? Quanto custa essa matéria-prima e dá um acréscimo em cima do preço; e a gente faz reunião para que todo o mundo use aquele preço.(...) A própria Associação, através das feiras livres e através dos supermercados, que a gente faz a pesquisa vê mais ou menos o quanto tá custando, fica mais ou menos; a diferença é pouca da materiaprima de um lugar para outro, aí a gente faz o cálculo e aí elas fazem um preço tabelado.(...) É colocada uma margem de lucro de $50 \%$, que é um preço altamente justo porque é chuva, suor, sereno e luta, tá? Que elas ficam aqui o dia inteiro passando por uma situação que não é fácil.

Além dos custos dos produtos, a presidente afirma que são levadas em consideração outras despesas, como locomoção, descartáveis, energia, entre outros, e o cálculo é feito pelo custo unitário. O objetivo desse preço tabelado é evitar a concorrência pela oferta 
de menor preço. De acordo com a Associação, a concorrência entre as tapioqueiras deve ser estabelecida em função do sabor do produto oferecido e o marketing desenvolvido por cada uma.

O estudo apresentado buscou, dentro da sua proposta, conhecer o entedimento da terminologia contábil na percepção das tapioqueiras. Para tal foi perguntado o significado das palavras: custo, despesa, receita e lucro, por serem palavras comumente utilizadas por comerciantes. Mais de 84\% afirmaram conhecer as palavras despesa, receita e lucro; entretanto, a palavra custo só foi reconhecida por $66 \%$ das respondentes. Os significados apresentados pelas tapioqueiras para estas palavras estão demonstrados nas Tabelas 7, 8, 9 e 10, a seguir:

\section{Tabela 7 - Significado da Palavra Custo}

\begin{tabular}{|l|c|c|c|}
\hline $\begin{array}{c}\text { Significado da } \\
\text { palavra Custo }\end{array}$ & Frequência & Percentual & $\begin{array}{c}\text { Percentual } \\
\text { Acumulado }\end{array}$ \\
\hline Custo Contábil & 3 & 14,3 & 14,3 \\
\hline Preço de Produtos & 13 & 61,9 & 76,2 \\
\hline Dinheiro & 1 & 4,8 & 81,0 \\
\hline Não sabe responder & 4 & 19,0 & 100,0 \\
\hline Total & 21 & 100,0 & \\
\hline
\end{tabular}

De acordo com o Holanda (2004), custo é o que deve ser despendido (em dinheiro, tempo, esforço, etc.) para se obter algo. A percepção de 61,9\% das tapioqueiras coincide com essa definição, como relata os repondentes T14 e T16. Apenas 14,3\% dos respondentes compreende custos com o mesmo significado conceitualmente estabelecido pela Contabilidade.

T14: O custo que eu acho é o custo do alimento, se é mais caro ou mais barato, né? Procurar o preço que seja mais barato né?

T16: Custo de vida, saber o que é viver e saber o quanto custou aquilo ali e quanto tem que pagar.

Tabela 8 - Significado da Palavra Despesa

\begin{tabular}{|c|c|c|c|}
\hline $\begin{array}{c}\text { Significado da } \\
\text { Palavra Despesa }\end{array}$ & Frequência & Percentual & $\begin{array}{c}\text { Percentual } \\
\text { Acumulado }\end{array}$ \\
\hline Custo Contábil & 5 & 16,1 & 16,1 \\
\hline
\end{tabular}




\begin{tabular}{|l|c|c|c|}
\hline Gastos Pessoais & 3 & 9,7 & 25,8 \\
\hline Despesa Contábil & 2 & 6,5 & 32,3 \\
\hline Gastos Pessoais e Com o negócio & 15 & 48,4 & 80,6 \\
\hline Gastos com o Negócio & 6 & 19,4 & 100,0 \\
\hline Total & 31 & 100,0 & \\
\hline
\end{tabular}

Na percepção das tapioqueiras em relação ao significado da palavra despesa, destaca-se o fato de $48,4 \%$ dos entrevistados considerarem os gastos pessoais e os gastos com o negócio como despesas a serem pagas. Este resultado poderia caracterizar o descomprometimento com o Príncipio da Entidade, entretanto os respondentes T13 e T16 explicam como é feita a distinção:

T13: Despesa tem um monte: de casa, despesa de casa e despesa do dia a dia que a gente tem que repor as coisas da tapioca pra depois pagar as contas.

T16: Despesa do dia a dia que tem que gastar consigo mesmo e material que é investimento; é o que a gente tem que deixar em casa pra pagar as contas.

\section{Tabela 9 - Significado da Palavra Receita}

\begin{tabular}{|l|c|c|c|}
\hline \multicolumn{1}{c|}{$\begin{array}{c}\text { Significado da } \\
\text { Palavra Receita }\end{array}$} & Frequência & Percentual & $\begin{array}{c}\text { Percentual } \\
\text { Acumulado }\end{array}$ \\
\hline Culinária & 14 & 51,9 & 51,9 \\
\hline Receituário Médico & 2 & 7,4 & 59,3 \\
\hline Receita Federal & 1 & 3,7 & 63,0 \\
\hline Receita Contábil & 3 & 11,1 & 74,1 \\
\hline Culinária e Receita Federal & 2 & 7,4 & 81,5 \\
\hline Despesa & 1 & 3,7 & 85,2 \\
\hline Culinária, Remédio e Receita Federal & 1 & 3,7 & 88,9 \\
\hline Culinária e Remédio & 2 & 7,4 & 96,3 \\
\hline Remédio e Receita Federal & 1 & 3,7 & 100,0 \\
\hline Total & 27 & 100,0 & \\
\hline
\end{tabular}

O significado da palavra receita foi apresentado pela maioria como os ingredientes necessários ou o modo de preparo de uma tapioca ou um bolo por $51,9 \%$. Outros signi- 
ficados bastante atribuídos foram: receita enquanto receituário médico para compra de remédios ou modo de administrar um medicamento; e Receita Federal, não como um indicativo de representatividade de órgão governamental, mas por ser comumente noticiada nos veículos de comunicação do País. Por outro lado, receita dentro da termilogia contábil foi apresentado por apenas $11,1 \%$ dos entrevistados. Os repondentes T30 e T16 comentam a respeito:

T30: Receita são... vamos supor vários ingredientes pra fazer um bolo. A gente tem que formar uma receita pra fazer um bolo.

T16: Têm vários tipos de receita: receita de remédio pra saber direitinho como tem que tomar, receita de comida, receita assim... de um conselho que você dá pra pessoa fazer.

\section{Tabela 10 - Significado da Palavra Lucro}

\begin{tabular}{|l|c|c|c|}
\hline $\begin{array}{c}\text { Significado da } \\
\text { Palavra Lucro }\end{array}$ & Frequência & Percentual & $\begin{array}{c}\text { Percentual } \\
\text { Acumulado }\end{array}$ \\
\hline Apurado & 8 & 26,7 & 26,7 \\
\hline Lucro Contábil & 16 & 53,3 & 80,0 \\
\hline Coisa Boa & 6 & 20,0 & 100,0 \\
\hline Total & 30 & 100,0 & \\
\hline
\end{tabular}

A maioria dos respondentes, 53,3\%, associaram o lucro ao resultado positivo entre as vendas (receitas) menos todo o dinheiro gasto para repor mercadorias, pagar o pessoal, as taxas e outras despesas (custos e despesas). A palavra apurado, utilizada por 26,7\% das tapioqueiras como sinônimo de lucro, é representada pelo faturamento diário ou mensal. Observou-se também que $20,0 \%$ das tapioqueiras, embora não soubessem explicar o significado da palavra lucro, consideram como sendo uma "coisa boa", reafirmando uma das definições de Holanda (2004) de que lucro é o ganho, vantagem ou benefício que se obtém de alguma coisa, ou com uma atividade qualquer. Os respondentes T16, T30 e T11 exemplificam a forma de calcular o lucro:

T16:Quem mais sabe de lucro sou eu! Se eu botei $R \$ 300,00$ de material e vendi $R \$ 700,00$ meu lucro foi de $R \$ 400,00$.

T30: É o que sobra, vamos supor, digamos que eu gastei $R \$ 100,00$ e aí eu vendi $R \$ 200$, sobrou $R \$ 100,00$, que é o lucro. 
T11: Eu sei que o apurado não é lucro, porque do que eu apurei eu tenho que tirar pra comprar material, pra pagar o rapaz do coco, por exemplo... e tem que pagar a prefeitura, a luz... tem que tirar tudo pra depois eu vê o que sobrou, que é o lucro da gente.

Observou-se através dessa pesquisa que os significados apresentados pelas tapioqueiras nem sempre coincidem com o adotado na contabilidade, entretanto, não deixam de ter um sentido lógico, em função da atividade exercida e o nível de escolaridade por elas apresentado. Destaca-se o significado da palavra lucro, pois, para $53,3 \%$, o sentido é o mesmo apresentado pela contabilidade ao determinar o lucro opeacional bruto de uma entidade, apesar de a maioria considerar como despesas os gastos pessoais misturados com os da barraca.

\section{CONCLUSÃO}

A pesquisa analisou aspectos relacionados à identificação das $C$, à identificação das práticas de controle financeiro e patrimonial e ao uso ao conhecimento da linguagem contábil desse grupo de comerciantes.

Constatou-se que as pessoas envolvidas nesse tipo de atividade, em geral, são do sexo feminino, que encontram na tapioca um meio de sustentabilidade, uma vez que, independentemente da idade, boa parte comercializa no mesmo local há mais de 15 anos. Verificou-se que a maioria cursou o ensino fundamental, no todo ou em parte, entretanto, a pouca escolaridade não é impeditivo para que elas procurem fazer cursos de aperfeiçoamento visando à melhoria e à continuidade do negócio.

Foi percebido que, mesmo estando no século XXI, as tapioqueiras do Alto da Sé de Olinda utilizam em seu negócio uma contabilidade empírica, cujo pensamento contábil assemelha-se ao das antigas civilizações. Observou-se que controle patrimonial é feito por meio da percepção e conhecimento do negócio ou por meio de anotações simplificadas; não há volume de estoque; os custos dos produtos estão diretamente relacionados à qualidade das mercadorias adquiridas, uma vez que a concorrência é estabelecida pela qualidade dos produtos oferecidos, visto que a precificação é padronizada.

Ao analisar a relação entre a percepção das tapioqueiras e os conceitos teóricos contábeis, buscou-se através da semiótica compreender o significado da terminologia custo, despesa, receita e lucro para a amostra selecionada. Constatou-se que a palavra lucro na ótica desses comerciantes possui o mesmo significado de lucro operacional bruto utilizado pela Contabilidade. Já os significados de despesa e custo para muitas estão misturados ao conceito de valor de um determinado objeto ou serviço, podendo ser este comercializado, ou não, por elas. Contudo, a receita é relacionada à instrução a ser seguida para se obter um resultado. 
Assim, a conclusão apresentada por esse estudo é que o controle patrimonial desenvolvido pelas tapioqueiras do Alto da Sé da cidade de Olinda acontece por meio de uma lógica própria, empírica, não uniformizada.O pensamento contábil se revela em sua forma elementar e com interpretações diferentes para os signos apresentados pela terminologia contábil.

Os resultados apresentados por esse estudo, apesar de limitado a um único ramo de atividade, podem representar um indicativo do que ocorre com outros grupos de microempresários, contribuindo para identificar as práticas de controle econômico-financeiro e o uso ou conhecimento da linguagem contábil pelos pequenos comerciantes.

Para futuras pesquisas, recomenda-se a avaliação em outros grupos dentro do contexto nacional, servindo esses estudos para que os contadores atentem para os microempresários, os quais, no contexto nacional, têm importância econômica, pela sua participação na economia e, no mercado informal, como amenizador do desemprego e das crises econômicas.

\section{REFERÊNCIAS}

ABAM - Associação Brasileira de Produtores de Amido de Mandioca. www.abam.com. br. Acesso: 05/07/2009.

ATAAA - Associação das Tapioqueiras e Artesões de Arte e Artesanato do Alto da Sé e de Olinda Geral. Entrevista com Sandete Ferrão em 09/07/09.

CARVALHO, Carlos Eduardo; ABRAMOVAY, Ricardo. O Difícil e Custoso Acesso ao Sistema Financeiro. In: Sistema Financeiro e as Micro e Pequenas Empresas: Diagnósticos e Perspectivas. 2. ed. Brasília: SEBRAE, 2004.

CIA, Joanília Neide de Sales; SMITH, Marinês Santana Justo. O papel da contabilidade gerencial nas PMES (pequenas e médias empresas): um estudo nas empresas de calçados de Franca-SP. In: ENCONTRO ANUAL DA ANPAD, 25., 2001, Campinas. Anais... Campinas: Associação Nacional de Programa de Pós-Graduação em Administração, 2001, 1 CD-ROM.

CUNNINGHAM, L. A. Semiotics, Hermeneutics and Cash: An essay on the True and Fair View. Boston College Law School-Research Paper Series, n. 06, p. 1-28, 2003.

DIAS, Cristiane B. P. de Araujo. et al. Ruídos na Comunicação entre a Contabilidade e os seus usuários 2004. Disponível em: www.congressoeac.locaweb.com.br/artigos42004/160.pdf. Acesso: 25/04/09. 
DIAS FILHO, José Maria, NAKAGAWA, Masayuki. Análise do Processo da Comunicação Contábil: Uma contribuição para a solução de problemas semânticos, utilizando conceitos da teoria da comunicação. Revista Contabilidade \& Finanças - USP, São Paulo, n.26, p.42-57, maio/agosto 2001.

Reflexões sobre a Dimensão Semiótica da Análise de Balanços:

Uma Contribuição à Otimização de Decisões de Crédito. 2002. Disponível em: www. anpad.org.br/evento.php?... Acesso: 25/04/09

A Compreensibilidade da Evidenciação Contábil: um convite a estudos baseados em semiótica e teoria da comunicação. Revista do Instituto de Estudos Contábeis, Feira de Santana -BA, v. 01, n. 01, p. 31-42, 2003.

ECO, Humberto. Tratado Geral de Semiótica. 3. ed. São Paulo: Perspectiva, 2000.

ETHERIDGE, Harlan L. An Examination of Semiotic Theories of Accounting Accruals. Unpublished Ph.D. dissertation, The University of Tennessee, Knoxville, 1990.

FAURE, Ives-André. A Respeito de Alguns Desafios Contemporâneos da Informalidade Econômica. Aproximando a Africa Ocidental e o Brasil. Chaiers Du GRES, Bordeaux, IFReDE, n.2006-8, fevereiro 2006.

HENDRIKSEN, Eldon S.;VAN BREDA, Michael F. Teoria da Contabilidade. 5. ed. São Paulo: Atlas, 1999.

HOLANDA, Aurélio Buarque de. Novo Aurélio Século XXI - O Dicionário da Língua Portuguesa. 3. ed. São Paulo: Fronteira, 2004.

ILUFI, Oscar Manuel Vegara. Teoria da Comunicação e Teoria da Semiótica: Sua Incorporação ao Processo de Formação Universitária do Contador no Chile. Conferência Acadêmica Permanente de Pesquisa em Contabilidade XI Assembleia Anual - Talca, 2000. Disponível em: www7.rio.rj.gov.br/cgm/comunicacao/textos/conhecimento/arquivos.pdf. Acesso em: 25/04/2009.

IUDíCIBUS, Sergio de. Teoria da Contabilidade. 7. ed. São Paulo: Atlas, 2004.

KAM, Vernon. Teoria da Contabilidade. São Paulo, 1985. 
KASSAI, Silvia. As Empresas de Pequeno Porte e a Contabilidade. Caderno de Estudos, São Paulo, FIPECAFI, v.9, n.15, p.60-74, janeiro/junho 1997.

LAUTIER, B. et all. L'État et L’Informel. Paris. L'Harmattan, 1991.

LINS,Vanessa. Tapioca: Alimento que virou patrimônio. Jornal Folha de Pernambuco. Publicação: 18/11/2006.

LIKOUROPOULOS, Milena Beatrice. O Comércio de Tapioca na Orla Marítima de Maceió: Uma Análise sob a ótica do desenvolvimento turístico local. 2006. Disponível em: 25/04/2009.

MARTINS, Eliseu. Contabilidade de Custos. 7. ed. São Paulo: Atlas, 2000.

MARTINS, Maria de Fátima Oliveira. Um Passeio na Contabilidade, da Pré-História ao Novo Milênio. Bélem, Adcontar, v-2,nº 1, p.7-10, maio 2001.

MORAES, Marcelo Botelho da Costa; NAGANO, Marcelo Seido; MERLO, Edgar Monforte. Mensuração da Semiótica na Codificação das Demonstrações Contábeis por Meio de Redes Neurais. 2004. Disponível em: www.congressousp.fipecafi.org/artigos42004/324. pdf. Acesso em: 25/04/2009.

NAKAGAWA, M.; PRETTO, C. B. M. An interdisciplinary view of accountancy in Brazil. In: Anais Asian-Pacific Conference on International Accounting Issues, 12th. Beijin, China, 2000.

NERI, Marcelo. Negócios Nanicos: problemas e percepções. Revista Conjuntura Econômica, setembro de 2005.

OLIVEIRA, Hebert E. MARTIN, Charles. Accounting Problems Encountered In Small Business Failures. Southwest Small Business Institute Association - SSBIA, 1993.

PAMPLONA, João Batista. ROMERO, Maria do Carmo. Desvendando o Setor Informal: relatos de uma experiência brasileira. Revista da ABET, 2003. Disponível em: WWW.race. nuca.ie.ufrj.br. Acesso: 14/04/2009.

PANHOCA, Luiz. NAKAGAWA, Masayuki. ACCIOLY Jr., Horácio. SILVA, Olga M. P. A Representação das Palavras Contabilidade, Custos e Investimentos para os Universitários e Profissionais da Área Econômica/Financeira. Revista Contabilidade \& Finanças - USP, São Paulo, n.35, p.45-53, maio/agosto 2004. 


\section{repec}

Revista Veja - O Melhor de Recife, 2008. www.vejasaopaulo.abril.br/red/blogs/omelhordobrasil. Acesso: 05/07/2009.

BRASIL. SECRETARIA DO PATRIMÔNIO, CIÊNCIA, CULTURA E TURISMO. Disponível em: www.olinda.pe.gov.br Acesso em: 30/06/2009.

SILVA, Benedito G. da. Sistema de informação contábil sob a ótica da teoria da comunicação: um estudo com administradores na região da Grande São Paulo. Dissertação de Mestrado apresentada à FEA/USP, São Paulo, 1995.

SCHMIDT, Paulo. História do Pensamento Contábil. Porto Alegre: Bookman, 2000.

SEBRAE. Economia Informal Urbana - Observatório SEBRAE julho de 2005. Disponível em: www.sebrae.com.br-estudosepesquisas Acesso em: 30/06/09. 